\title{
Adsorption Isotherm Study of Cd(II) by Polyamine Wheat Straw Cellulose
}

\author{
Qingshan Pan, Xianlan Chen, Ling Shi , Heping Yan Bo Zhou, Shijuan Xu, Jing Wang, Gaozhang Gou, Na Wu, \\ Dushu Huang, Yunhui Long,Wei Liu* \\ School of Science, Honghe University, Mengzi, Yunnan, 661199, CHINA
}

\begin{abstract}
Wheat Straw Cellulose (WSC) modified by diethylenetriamine was investigated as an adsorbent for Cd(II) removal from aqueous solution. The preparing parameters on preparation of Polyamine Wheat Straw Cellulose (PWSC) were optimized. The effects of $\mathrm{pH}$, adsorbent dose, contact time and initial concentration on the Cd(II) removal process were studied by using batch methods. The maximum adsorption capacity of $\mathrm{Cd}(\mathrm{II})$ onto PWSC was found to be $21.37 \mathrm{mg} / \mathrm{g}$ and the removal percentage was more than $90 \%$. The adsorption isotherms were analyzed using the Langmuir and Freundlich isotherms. The results showed that the adsorption process was well described by Langmuir isotherm model with correlation coefficients (R) of $\mathbf{0 . 9 9 8 1}$ for $\mathrm{Cd}(\mathrm{II})$ adsorption.
\end{abstract} Cd(II).

Keywords- Wheat Straw Cellulose, Polyamine, Adsorption,

\section{INTRODUCTION}

Removal of Cd(II)in waste water has become urgent issue in environmental protection1. A long list of methods is available for the removal of $\mathrm{Cd}(\mathrm{II})$ such as chemical precipitation, ion exchange resin, electrochemical reduction method and activated carbon adsorption[12].The agricultural wastes such as wheat straw, peanut shell, cotton, corn cob etc. have a natural capacity for adsorption of heavy metal ions because they have some natural group and micro-pore structure for ion-exchange adsorption[3-4]. In this paper, The Wheat Straw Cellulose (WSC) was modified by diethylenetriamine to prepare Polyamine Wheat Straw Cellulose (PWSC), The absorption of Cd(II)in water by PWSC was tested. The effects of $\mathrm{pH}$, adsorbent dose, initial concentrations of Cd(II) and adsorption time on adsorption of Cd(II) were studied providing theoretical basis for removal of $\mathrm{Cd}(\mathrm{II})$ by chemically modified cellulose based agricultural wastes materials. The adsorption properties of PWSC were studied. Isotherm models (Freundlich and Langmuir) were employed to describe the experimental data.

\section{MAterial AND MethodS}

\section{A. Reagents}

Wheat Straw, Diethylenetriamine (AR), $\quad \mathrm{K}_{2} \mathrm{Cr}_{2} \mathrm{O}_{7}$ (AR), Sodium hydroxide (AR) Sodium carbonate (AR) and Epoxy chloropropane (AR) were used.

\section{B. Preparation of PWSC.}

The Wheat Straw (WS) was washed clean, dried and grinded to powder before preparation. Take a certain amount of WS and sodium hydroxide into a flask and mix with some distilled water. After reaction for $2 \mathrm{~h}$ at room temperature, drain the filtrate, add $10 \%$ sodium hydroxide solution and a certain amount of epoxy chloropropane into the reaction flask, then heat for $8 \mathrm{~h}$, filter, wash for $1 \sim 2$ times with acetone, dry at $75^{\circ} \mathrm{C}$ after filtering, get epoxidation of WSC (EWSC). Add EWSC and diethylenetriamine (1:1 by mass) in the reaction flask and add $200 \mathrm{~mL}$ water, $2 \mathrm{~g}$ sodium carbonate at a certain temperature reaction for $3 \mathrm{~h}$, wash to neutral, dry to constant weight at $75{ }^{\circ} \mathrm{C}$, get Polyamine Wheat Straw Cellulose (PWSC).

\section{Equilibrium Adsorption Isotherms.}

The Freundlich Isotherm Model and Langmuir Isotherm Model were employed to describe the adsorption process. The linearized forms of Freundlich isotherm model and Langmuir isotherm model[5] are given as:

Freundlich Isotherm Model:

$$
\log q_{e}=\log K_{F}+\frac{1}{n} \log C_{e}
$$

where $\mathrm{K}_{\mathrm{F}}$ and $\mathrm{n}$ are Freundlich constants representing the adsorption capacity and intensity of adsorption. The adsorption capacity $\left(\mathrm{K}_{\mathrm{F}}\right)$ and the adsorption intensity $(1 / \mathrm{n})$ are directly obtained from the slope and the intercept of the linear plot of $\log \mathrm{q}_{\mathrm{e}}$ versus $\log \mathrm{C}_{\mathrm{e}}$.

Langmuir Isotherm Model:

$$
\frac{C_{e}}{q_{e}}=\frac{1}{q_{\max } b}+\frac{C_{e}}{q_{\max }}
$$

where $\mathrm{q}_{\max }$ is the maximum adsorption capacity and $\mathrm{b}$ is the equilibrium Langmuir constant related to adsorption energy. A dimensionless constant called separation factor $\left(\mathrm{R}_{\mathrm{L}}\right)$ describing the essential characteristics of the Langmuir isotherm is calculated using the formula[6] :

$$
R_{L}=\frac{1}{1+b C_{0}}
$$

where $\mathrm{C}_{0}$ is the initial concentration of $\mathrm{Cd}(\mathrm{II})$. The $\mathrm{R}_{\mathrm{L}}$ value indicates the isotherm to be either unfavorable $\left(R_{L}>1\right)$, linear $\left(R_{L}=1\right)$, favorable $\left(0<R_{L}<1\right)$, or irreversible $\left(\mathrm{R}_{\mathrm{L}}=0\right)$. 


\section{RESUlts AND DiscUSSION}

\section{A. Optimization of preparation}

The effects of the sodium hydroxide $(20-50 \mathrm{~g} / \mathrm{L})$, epoxy chloropropane $(1-10 \mathrm{ml})$ and reaction time (1-5h) on the preparation of PWSC adsorbent were investigated. The results suggested that the mpg was maximum when the sodium hydroxide was $30 \mathrm{~g} / \mathrm{L}$, the Epoxy chloropropane was $6 \mathrm{ml}$ and the reaction time was $8 \mathrm{~h}$.

\section{B. Effect of solution $\mathrm{pH}$}

The removal of Cd(II) from wastewaters by adsorption is highly dependent on the $\mathrm{pH}$ of solution. The solution $\mathrm{pH}$ can affect the surface charge of the adsorbent, the degree of ionization and the speciation of Cd(II) ions. When Cd(II)aqueous solution concentration was at 100 $\mathrm{mg} \cdot \mathrm{L}^{-1}$ and volume was $200 \mathrm{~mL}$, contact time was $2 \mathrm{~h}$, The effect of $\mathrm{pH}$ on adsorption capacities was investigated in the range 2.0-8.0. The results suggested that when $\mathrm{pH}$ of aqueous solution was at 4.5 , the removal efficiency was maximum. The $\mathrm{pH}$ of the solution affects the adsorptive process through protonation and deprotonation of functional groups of the active sites of the adsorbent surface. $\mathrm{H}^{+}$competes with metal cations for the available adsorption site. The optimum $\mathrm{pH}$ value was found to be 4.5 .

\section{Effect of dose.}

The amount of PWSC adsorbent for Cd(II) removal was studied by changing the dose of adsorbent from 1.0 to $14.0 \mathrm{~g} / \mathrm{L}$ while the concentration of Cd(II) was $100 \mathrm{mg} / \mathrm{L}$ and the volume was $200 \mathrm{~mL}$ without change. The results show that the removal percentage of PWSC increases with increasing of the amount of adsorbent at first. When the dose of adsorbent was $6 \mathrm{~g} / \mathrm{L}$, the removal percentage was maximum, it was $92.58 \%$. This is an optimum dosage beyond which the value of efficiency does not significantly change. Because the concentration of initial Cd(II)was fixed and the adsorbent was excessive when the amount of adsorbent overran the optimum dosage. so when the amount of adsorbent was more than $6 \mathrm{~g} / \mathrm{L}$, the equilibrium adsorption capacity did not increase.

\section{Effect of initial concentration:}

The removal percentage of Cd(II) by PWSC powder was tested at different initial concentrations $(10-100 \mathrm{mg} / \mathrm{L})$ of Cd(II) at a fixed condition adopted above. The results suggested that the Cd(II) adsorption is significantly influenced by the initial concentration of $\mathrm{Cd}(\mathrm{II})$ in aqueous solution. The removal percentage was reduced with initial concentration of Cd(II) increasing. It may be due to when the PWSC was added at a certain dose, the active adsorption sites of the absorbent were in certain quantities. When the absorption process reached a balance saturation point, $\mathrm{Cd}(\mathrm{II})$ ions in aqueous solutions increased with the initial concentration, so the removal percentage decreased with the increasing of the initial concentration.

\section{E. Adsorption Isotherms}

Freundlich isotherm and Langmuir isotherm for Cd(II) adsorption process are shown in fig. 1 and fig.2. The related parameters of the isotherms are given in table 1 . Investigation of the isothermal characteristics shows that Cd(II) removal by PWSC is in high accordance with Langmuir isotherm by comparing the correlation coefficients(R), Langmuir isotherm provides a good model for the adsorption system which describes a monolayer adsorption onto the surface of the adsorbent with finite number of identical sorption sites. The maximum adsorption capacity of Cd(II) found was $21.37 \mathrm{mg} / \mathrm{g}$, the value of the dimensionless parameter $\mathrm{R}_{\mathrm{L}}(0.21)$ indicates that the adsorption is favorable $\left(0<\mathrm{R}_{\mathrm{L}}<\right.$ $1)$.

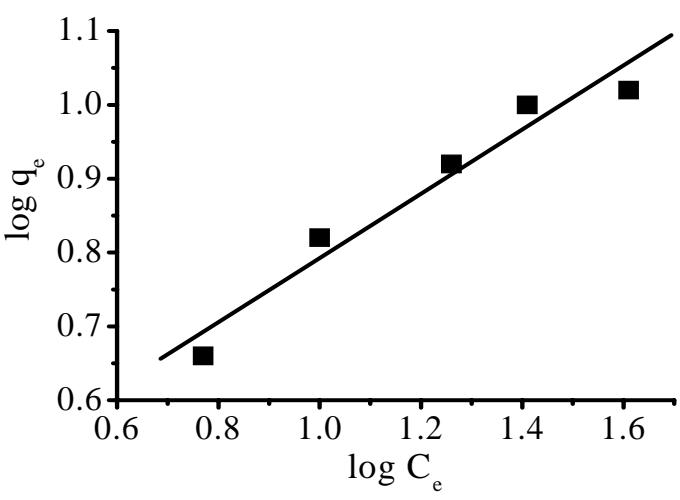

Figure. 1: Fitting of adsorption data with Freundlich isotherm

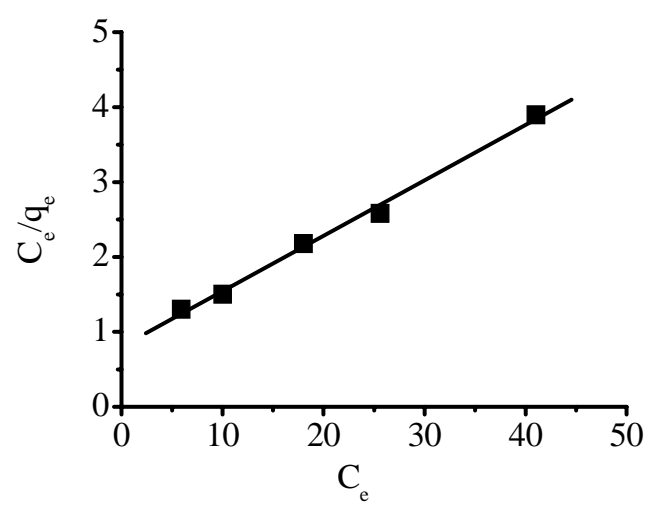

Figure. 2: Fitting of adsorption data with Langmuir isotherm

TABLE 1 PARAMETERS OF ADSORPTION ISOTHERM MODELS

\begin{tabular}{|c|c|c|c|c|c|c|}
\hline \multicolumn{2}{|c|}{ Freundlich isotherm } & \multicolumn{4}{|c|}{ Langmuir isotherm } \\
\hline $\mathrm{n}$ & $\mathrm{K}_{\mathrm{F}}$ & $\mathrm{R}$ & $\mathrm{q}_{\max }(\mathrm{mg} / \mathrm{g})$ & $\mathrm{R}_{\mathrm{L}}$ & $\mathrm{b}$ & $\mathrm{R}$ \\
\hline 2.23 & 2.15 & 0.9653 & 21.37 & 0.23 & 0.091 & 0.9981 \\
\hline
\end{tabular}




\section{CONCLUSION}

In summary, the results described above indicate that the PWSC adsorbent has a good adsorption capacity for $\mathrm{Cd}(\mathrm{II})$ from aqueous solutions. The removal percentage of Cd(II) was more than $90 \%$ and the max. equilibrium adsorption capacity was $21.37 \mathrm{mg} / \mathrm{g}$, compared with the similar adsorbent, the adsorption capacity was improved obviously. The obtained results showed that the Langmuir isotherm model is the best fitting model with the experimental data with high $\mathrm{R}$ value. So it can be used for removal of $\mathrm{Cd}(\mathrm{II})$ from wastewaters and industrial effluents to overcome water pollution as a highly effective, non-hazardous and low cost adsorbent. Continuing research may lead to the development of green technologies for utilizing cellulose in water pollution treatment area.

\section{ACKNOWLEDGEMENT}

This research was supported by National Natural Science Foundation of China (61361002 and 21366011), Yunnan Provience Science and Technology Projects (2013FZ121 and 2012FD053) and Scientific Research
Foundation of Education Department of Yunnan Provience (2012Y451).

\section{REFERENCES}

[1]. Lakshmipathiraj P., Raju G. B., Basariya M. R., Parvathy S. and Prabhakar S., Removal of Cd(II)by electrochemical reduction, Sep. Purif. Technol., 60, 96-102 (2008)

[2]. Gode F. and Pehlivan E., Removal of Cd(II) from aqueous solution by two Lewatitanion exchange resins, J. Hazard. Mater., B119, 175-182 (2005)

[3]. Gerente C., Lee V. K. C., Cloirec P. Le and McKay G., Application of chitosan for the removal of metals from wastewaters by adsorption-mechanisms and models review, Crit. Rev. Environ. Sci. Technol., 37, 41-127 (2007)

[4]. Zheng L., Dang Z., Yia X. Y. and Zhang H., Equilibrium and kinetic studies of adsorption of $\mathrm{Cd}(\mathrm{II})$ from aqueous solution using modified corn stalk, J. Hazard. Mater., 176, 650-656 (2010).

[5]. Miretzky E. P. and Cirelli A. F., Cd(II)and Cr (III) removal from aqueous solution by raw and modified lignocellulosic materials: a review, J. Hazard. Mater., 180, 1-19 (2010)

[6]. Zheng L., Dang Z., Yia X. Y. and Zhang H., Equilibrium and kinetic studies of adsorption of $\mathrm{Cd}(\mathrm{II})$ from aqueous solution using modified corn stalk, J. Hazard. Mater., 176, 650-656 (2010). 